\title{
ENTRE LA COSTA DE COBIJA Y TIERRAS ALTAS. EL TRÁFICO ARRIERO A INICIOS DE LA REPÚBLICA BOLIVIANA*
}

\author{
BETWEEN THE COBIJA COAST AND THE HIGH LANDS. MULE TRAFFIC \\ IN THE STARTER BOLIVIAN REPUBLIC
}

\author{
Javiera Letelier Cosmelli**
}

\begin{abstract}
Desde la configuración del Puerto de Cobija hasta la guerra del Pacífico, tanto indígenas como bolivianos y extranjeros establecieron relaciones en el marco de un contexto cambiante y complejo tanto a nivel nacional como internacional en donde se introduce la economía capitalista industrial. Es en ese marco que los arrieros y la movilidad entre costa y tierras altas se constituyeron en piezas claves para dar vida a Cobija y resto de Atacama. A partir de este escenario realizamos una revisión relativa al uso y readecuación de prácticas de movilidad arriera entre costa y tierras altas de Atacama considerando la dinámica transfronteriza que adquieren estas prácticas y sus implicancias socioculturales a inicios del periodo republicano.
\end{abstract}

Palabras claves: Puerto de Cobija, tierras altas, economía capitalista industrial, Arrieros, movilidad

From the creation of the Port of Cobija until the begining of the Pacific War, indigenous, bolivians and foreigners, had a significative role in a changing and complex context related with the industrial capitalism economy in a national and international scene. In this structure, muleteers and their movility between coast and high lands was transformed giving life to Cobija and the rest of Bolivia. With this background we review the use and transformation of the movility practices between coast and Atacama High lands considering the transfrontier dynamic that acquires this practice and its socio cultural implications during the early days of the Republic.

Key words: Cobija Port, Hight lands, industrial capitalism economy, muletters, movility.

\section{Introducción}

La creación de un puerto en Cobija emergió con el Estado boliviano, siendo uno de sus principales objetivos potenciar el desarrollo comercial e industrial de esta nueva nación (Ayllón 2007). Es en ese contexto que en diciembre de 1825 nació el Puerto Lamar en la costa de Atacama y, consecuentemente, se incentivaron las rutas de comunicación con el objeto de activar el tráfico arriero y la circulación hacia el interior de la República, el noroeste argentino, el sur de Perú y el norte chileno.

Es en ese marco que la arriería fue un elemento central en el desarrollo de la región atacameña, ya que constituyó la operacionalización de la conectividad entre el altiplano y el resto del mundo. Esta actividad correspondió a una labor asalariada de flete o transporte a lomo de mula de mercancías tanto de particulares como de funcionarios, "combinando el comercio y el intercambio" (Sanhueza y Gundermann 2007:129), destacando en el caso de Atacama una temprana introducción de población indígena a esta actividad por razones económicas (Sanhueza 1992a).

La arriería constituyó una actividad fundamental para el desarrollo social y económico de Atacama y requirió de un alto grado de especialización y conocimiento del territorio, la que se sustentó en una nueva forma de apropiación del espacio vinculada a la práctica colonial. Esto implicó "un proceso de dispersión y movilidad de la población" (Hidalgo 1984:311) motivadas por la economía monetaria colonial; proceso que pudo involucrar la ruptura con la comunidad de origen. Además se nutrió del conocimiento y formas de movilidad tradicional de grupos locales por el espacio andino dentro de la lógica de manejo de los diversos pisos altitudinales (Hidalgo 1984, Aldunate et al 2010)

Esta última perspectiva, como plantea Sanhueza (1992b), enriquece el modelo de Murra (2002) de "archipiélago vertical" planteándolo no solo desde una perspectiva ecológica sino que incluyendo el contexto social e histórico de cada comunidad.

\footnotetext{
* Resultado del proyecto FONDECYT No 1100951 y Anillos SOC1109.

** Universidad Alberto Hurtado, Santiago de Chile. Correo electrónico: javieraletelier@gmail.com
} 


\section{Antecedentes coloniales}

En Atacama el desarrollo de la arriería colonial comenzó "durante la segunda mitad del siglo XVI" (Sanhueza 1992a:363). El incentivo de esta práctica permitió el movimiento desde los centros mineros y productores hacia la costa y altiplano, además asintió que tempranamente los atacameños se insertaran en la estructura económica colonial accediendo al circulante necesario para cubrir las tasas tributarias (Sanhueza 1992a, Morales 2009, Borie 2013).

Durante el Periodo Colonial, la labor de los arrieros atacameños fue impulsada paulatinamente en la región por las autoridades españolas locales, entre las que se cuentan la Iglesia, en un principio, y luego los corregidores, situación que a inicios del siglo XVIII fue oficializado por medio de sistemas de reparto (Sanhueza 1992a).

Aunque para el siglo XVI se utilizó los camélidos como medio de carga, posteriormente durante la primera mitad del siglo VII se introdujo el ganado mular en la región y desplazó de forma relativamente rápido a las especies tradicionales (Sanhueza 1992a). Este desplazamiento respondió tanto a la presión de los corregidores por la venta de mulas, pero principalmente por las características de este animal según las condiciones ambientales y climáticas de Atacama (Sanhueza 1992a). La predilección de las mulas para actividades de trajín se debe a varias razones, entre las que se cuentan la capacidad de estas para cargar el doble de peso que las llamas (Conti y Sica 2011, Sica 2010, Barra 2006) y su mayor inteligencia y capacidad de soportar el hambre, la sequía y la altura que el caballo (Barra 2006). No obstante, para el periodo republicano en la costa se privilegió el uso del burro, que era aún más resistente que la mula (ANB, MI. Tomo 31, $\left.\mathrm{N}^{\circ} 22,1830\right)^{1}$.

Los primeros antecedentes coloniales que dan cuenta de la conexión entre costa, específicamente Cobija, y tierras altas se remontan al siglo XVI. Lozano de Machuca, factor de Potosí, nombra a la Ensenada de Atacama, correspondiente al actual sector de Cobija y da cuenta del tráfico de pescado en la región "ques donde esta el puerto, hay cuatrocientos indios pescadores uros, que no son bautizados ni reducidos, ni sirven a nadie, aunque a los caciques de Atacama dan pescado en señal de reconocimiento" (Lozano de Machuca 1885[1581]: XXV).
Posteriormente, el tráfico de pescado es referenciado en la Probanza de Méritos del cura Francisco de Otal situada entre 1591 y 1645 (Castro, 1997, 2009). En su obra, el presbítero reclama su habilidad en las diversas lenguas locales, su trabajo como extirpador de idolatrías, su labor evangelizadora y los envíos de pescado fresco que hacía al arzobispo de La Plata (Aldunate et al. 2010; Castro, 1997, 2009; Castro et al. 2012). Asimismo, Otal compró mulas para facilitar y promover la adquisición de estas a los arrieros, considerándolas un motor para mejorar la vida de la población local. El sistema de compra de mulas consistía en el endeudamiento con el sacerdote y la forma de pago se realizaba con fletes, destacando el transporte de productos como el pescado, el que era llevado hacia el mercado altiplánico y para proveer a las autoridades eclesiásticas (Sanhueza 2011).

El uso de Cobija continuó durante el siglo XVIII, constituyéndose como un puerto alternativo muy conocido por los contrabandistas franceses que recibían plata proveniente desde Potosí e intercambiaban por sus mercancías (Lofstrom, 1974, Rushenberger 1934).

\section{El surgimiento de la arriería republicana en la costa de Atacama}

Respecto de la arriería republicana su historia se remonta al período de las guerras de independencia, fue durante ese proceso que en la zona andina se observan una interrupción en los circuitos mercantiles habituales, motivadas por la disminución de la minería de la plata. Asimismo, esta desarticulación también recayó en las grandes esferas de monopolio comercial colonial, permitiendo el ascenso de la elite mercantil local. Élite, que se consolidó como poder político de los nuevos Estados-Naciones (Conti, 2008).

En 1825 se declaró la independencia del Alto Perú (Lofstrom, 1974) y se establecieron las bases del desarrollo republicano que tuvo como eje un sistema sociopolítico y económico en donde, por una parte, se mantuvieron aspectos coloniales como el sistema agrario, el tributo indígena, los gremios, entre otros; pero, por otra parte, en el comercio irrumpió el capitalismo industrial (Cajías, 1975).

Asimismo, durante este período se agregan complejidades a la actividad arriera, siendo el nuevo carácter transfronterizo que adquiere uno de los ejes para comprender la dinámica social, 
política y económica que comenzó a desarrollarse tanto en Atacama como en las regiones vecinas (Molina 2011).

Fue en esta dinámica en donde los límites políticos desestructuraron la lógica de movilidad en Atacama, siendo la creación del Puerto de Cobija fundamental para la reorganización de la movilidad terrestre y transmarítimos en una lógica de mercado al servicio del reciente Estado boliviano. En tal sentido, el nacimiento de Bolivia requirió de modo urgente el impulso de un puerto propio que permitiera ser parte del comercio transmarítimo y, así, fortalecer el intercambio comercial a escala mundial. En ese sentido, se comprende que un puerto no es solo un símbolo de nacionalismo, sino también una necesidad política y económica (Lofstrom, 1974), sobre todo en el contexto de que: "el Alto Perú, en 1825, se hallaba postrado económicamente como resultado de los trescientos años de explotación colonial y los dieciséis de lucha revolucionaria" (Lofstrom 2011: 65).

A fines de 1825 José Antonio Sucre desarrolló algunas reformas políticas y económicas que buscaron la revitalización de la minería de la plata por medio del establecimiento de un nuevo sistema administrativo en Bolivia. Este consistía en la introducción de capitales y tecnología extranjera con el objetivo de mejorar el transporte y la comunicación. Así, un puerto constituía la clave para el cumplimiento de estos objetivos (Lofstrom 1974), considerando que "Bolivia nace poblada en su corazón, pero vacía en sus confines y sin vías de comunicación" (Murillo 2001: 33).

A lo anterior se agrega otra complejidad asociada al establecimiento de un puerto en territorio boliviano. Durante el periodo colonial la zona del altiplano del Alto Perú se conectaba al litoral por la vía que va desde La Paz hasta Arica (Lofstrom, 1974), así, los productos del Alto Perú, especialmente, la plata era trasladada desde Potosí a La Paz a lomo de mula. Luego de la creación del virreinato de La Plata, en 1776, el mineral exportado y los productos de comercio importados diversificaron su área de movilidad conectándose también con las provincias argentinas y, por consiguiente, con Buenos Aires (Lofstrom, 1974). No obstante, durante el período republicano Arica quedó fuera de los límites de Bolivia, por lo que la ruta La Paz-Arica se vio obstaculizada. A ello se agrega la existencia de patrones comerciales establecidos entre la ruta recientemente nombrada junto con un marcado prejuicio por parte de los comerciantes nacionales respecto de la creación de un puerto más al sur de Arica (Lofstrom 1974).

Pese a lo anterior, a partir de la República, el comercio en la zona y, por tanto, las prácticas de movimiento e interacción social se articularon por los dos puertos del Pacífico, Cobija y Arica. Así, "desde Arica y Tacna se surtía el mercado de La Paz, desde Cobija las mercancías cubrían los mercados del sur, en especial Potosí y Chuquisaca, de donde eran revendidas al interior del sur boliviano" (Conti 2011: 26). Dicha dinámica se vio reimpulsada con el resurgimiento de centros mineros -como Potosí- y la rearticulación comercial con el noroeste argentino. Fue especialmente entre 1830 y 1860 que este tráfico arriero tuvo una importante conexión con Argentina. Esta relación se vio reforzada por razones políticas de ese país (Conti 2003a) y por la complementariedad que ofrecían zonas como Salta. Fue desde Argentina donde se obtuvo el ganado necesario, tanto para el transporte como su consumo siendo, por lo tanto, un elemento fundamental para el arrieraje y la movilidad de personas y productos. En ese sentido, como señala Quintian:

El ganado en pie continuó organizando el comercio interregional, pues era pagado en monedas de cobre y plata, insumo básico para los comerciantes salteños. Restablecido luego de la independencia, este tráfico integraba las provincias del norte: mulas criadas en Santiago del Estero, La Rioja, Catamarca y Tucumán, eran invernadas en Salta. Similar destino seguían los caballos, burros y vacas invernadas en las planicies cercanas a la quebrada de Humahuaca y en los valles Calchaquíes de donde abastecían el transporte, la carga y el consumo altoperuanos. Con los retornos en plata los grandes comerciantes salteños pagaban las importaciones en Cobija y Valparaíso para abastecer Salta y Jujuy (Quintian 2012: 23).

La relación con Argentina quedó reflejada en la observación de Atanasio Hernández sobre Cobija en 1830. En ella resalta la idea que por la ubicación de la ciudad de Salta -alejada de Buenos Aires-, los altos impuestos a los productos en ese mismo puerto y la inestabilidad de las provincias intermedias de Argentina, Cobija se convirtió en la opción portuaria más segura y económica. Asimismo, la relación que 
vinculó el Noroeste Argentino con Valparaíso estuvo mediatizada por Lamar (Conti 2003).

Esto además se vio reforzado desde Bolivia, ya que Salta ofrecía recursos como el ganado de caballos, mulas y burros, esenciales para el flete de productos (ANB MI. Tomo 31, $\mathrm{N}^{\mathrm{o}} 22,1830$ ). De este modo, La conexión del interior andino con el Pacífico a través del puerto de Cobija, permitió que se dinamizara un espacio de comercialización e integración cultural preexistente, pero que adquirió nuevas características en función de la masiva circulación de bienes y personas (Conti, 2011: 30).

Es así que en 1854, cuando el viajero Rudolfo Armando Phillipi llegó a Calama desde Cobija, señala lo siguiente...

No se cultiva otro grano que cebada para las mulas; pero las alfalfas ocupan la mayor parte del terreno cultivable, siendo el transporte de las mercancías de Cobija a las provincias Argentinas a Salta, Jujui, Tarija la ocupación principal de los Atacameños. Muy pocas mercancías se dirigen de Cobija hacia el interior de Bolivia por la Gran distancia; el puerto Natural de Bolivia es Arica, y Tacna puede considerarse como el Emporio de Bolivia. Por eso hay tantas mulas de Atacama y la tercera parte de los habitantes creo son arrieros. Los animales no se crían aquí se compran de los Argentinos al precio común de 30 a 40 pesos... (Phillipi 1860: 53).

\section{La habilitación del Camino de Cobija a Potosí a inicio de la República}

El camino de Cobija a Potosí poseía 188 leguas según Cajías (1975) y 150 leguas según Arce (1997). La implementación de este fue tremendamente compleja, ya que, aunque su trazado respondió a una vía que previamente era utilizada, no contaba con las comodidades necesarias para un tránsito constante. Entre los antecedentes previos al establecimiento formal de una vía en momentos republicanos, destacan menciones como las de O'Connor de los lugares donde posteriormente se establecieron algunas postas y que correspondían a los enclaves de pernocte utilizados durante la Colonia (Cajías, 1975).

La habilitación formal del camino comenzó en 1827 junto con el Puerto, así, en marzo de ese año,
Lucas de la Cotera, famoso empresario, junto con la verificación de su establecimiento en Cobija se le recomienda la labor de reconocimiento de los caminos hacia el interior. Es durante este reconocimiento que el gobierno solicitó a los gobernadores de Atacama y Lípez que se le aporte a Lucas de la Cotera y otros comisionados -como Inchausti y Fernández- la facilidades necesarias para dicha tarea (Cajías, 1975). Desde un punto de vista empresarial y con la intención de dar vida al tráfico, de la Cotera repartió 600 mulas a los habitantes de Calama y Chiuchiu, quienes "con la calidad a pagar 20 pesos en fletes, conforme se les ocupare después de 8 meses de plazo y descontándosele en cada viaje una tercera parte de ajuste" (Cajías, 1975: 69).

Posteriormente, en agosto de 1827 previo a la llegada de los primeros barcos a Cobija, el gobierno emanó a los gobernadores de Atacama y Lípez una orden para que verificaran las condiciones de la ruta a Potosí, considerando el forraje, la disponibilidad de tambos, y además solicitó que se enviaran a Cobija la cantidad de mulas necesarias para disponer de estas, de forma anticipada, cuando se enviara la carga al interior (Lofstrom, 1991).

Simultáneamente, el Prefecto de Potosí mandó a plantar forraje para el consumo de quienes utilizaran los caminos. Junto con lo anterior, se planteó la repartición temprana de los terrenos asociados a las postas con la intención de poblarlas. Además, se ofrecieron varios beneficios a quienes estuvieran dispuestos a esta dificultosa tarea como ayuda monetaria permanente de parte del gobierno, ofreciéndose esta misión a familias potosinas. A esto se suma la repartición de terrenos a los habitantes de la zona - cercanos a los caminos y de semillas de alfalfa-, con la intención de aumentar la disponibilidad de forraje (Cajías, 1975).

Análogamente, el periódico El Cóndor publicó unos cuantos artículos sobre el camino a Cobija que buscaban alentar la sensación de conexión entre el Alto Perú y el Litoral. Así, El Cóndor señaló algunos itinerarios -entre los que se cuenta Cobija-Potosí y Cobija-Oruro- que, pese a las condiciones naturales poco favorables de la ruta, eran posibles de transitar por iniciativas comerciales. Sin embargo, ninguna de las medidas tuvo un éxito perdurable: ni siquiera la importante intervención de los sacerdotes, quienes comenzaron a preocuparse de los transeúntes y la limpieza del camino, destacando el de San Cristóbal que, incluso, solicitó las postas bajo su dirección (Cajías, 1975). Por 
tanto, pese a los esfuerzos publicitarios y personales para el incentivo a la habilitación de la ruta, la conexión entre costa y altiplano no fue fluida (Cajías, 1975).

En ese sentido, las difíciles condiciones del camino generó que incluso las mulas, que se utilizaron desde Calama al interior, no fueran suficientes. Lo anterior quedó expresada en la observación de Atanasio Hernández de 1830, donde señala:

El tráfico jeneral y mas comodo de este Puerto para transportar los cargamentos al interior calculando la situacion de los caminos y pascanas, no puede ser de otro modo que por las arrias de Burros. En unos paises áridos adonde escasean los pastos y el agua, no es posible sostener grandes recuas de mulas que se necesitan. Es visto que los primeros son susceptibles de mantenerse con poco, sufre mas, y al fin ejecutan iguales jornadas que las mulas. Verdad és que la operacion de reducir los cargamentos á farditos de 21/2 @ es penosa, costosa, y morosa; mas tambien no es menor cierto que las mulas se aniquilan pronto, se cansan, y no pueden soportar la escaces de alimento van dejando el camino sembrado de despojos, resultando ruinas al arriero, y atrazos al comerciante (ANB MI. Tomo 31, $\mathrm{N}^{\mathrm{o}} 22,1830$ ).

Junto con las medidas anteriores como traer burros se establecieron varias estrategias de control de las rutas, una de las más relevantes fue la generación de un sistema de postas o tambos que, a lo largo del desarrollo histórico de Cobija, fueron persistentemente inestables. Las postas consistían en unas cuantas posadas con la presencia de un maestro, quien bajo un cobro aseguraba provisiones básicas tanto para los arrieros como sus recuas. En tanto, el postillón correspondía al servicio de guía, mantención y cuidados de las postas, que en una parte importante fue realizada por la población indígena (Mendieta 2006).

En una carta de Gaspar Aramayo del 15 de abril de 1829 da cuenta del "itinerario del Camino al Puerto Lamar con expresión de las postas que existen, las que deben construirse, lo psjes que tienen o no comodidad y sus distancias a saber" (ANB MI. Tomo 25, $\mathrm{N}^{\circ} 16,1829$ ). El itinerario establece que el camino de Potosí a Cobija contaba con 169 leguas y 19 postas. Dentro de los tramos en específico Aramayo señala:

Desde Potosí hasta la quinta posta de la Ollería todo el camino malo y componible á poco costo, todo en la provincia de Porco y de Vicigua á la Ollería hay una cuesta $\mathrm{q}^{\mathrm{e}}$ exije su composicion mas $\mathrm{q}^{\mathrm{e}}$ todo. De esta Posta adelante hasta Ascotan todo el camino admite rodados. La cordillera q. principia de Talota separa toda por quebradas y en adelante. La cuesta de Ascotan y obras con la mejor comodidad y termina en Pincullo q. dista quatro leguas de Ascotan $\mathrm{p}^{\mathrm{a}}$ adelante. La cuesta de Ascotan y la quebrada que baja atrás, todo necesita compocicion. Culupo en el medio de la trabesia $q^{\mathrm{e}}$ carece de todo recurso y adelante el camino por Tames es mas llano y algo mas corto con aorro de una empinadisima quebrada $\mathrm{q}^{\mathrm{e}}$ hoy sale de Cobija (ANB MI. Tomo 25, $\mathrm{N}^{\mathrm{o}} 16,1829$ ).

Pese a la falta de recursos, el gasto total de los 9 tambos correspondió, hacia enero de 1831, a 3.004 pesos (ANB MI. T. 70, N 36, 1831). Gabino Ibáñez, gobernador en esa fecha de Lamar, señaló, en noviembre de 1830 al Ministro del Interior de Bolivia, que todas las casas de postas de Atacama, correspondientes a nueve tambos, ya se encontraban terminadas desde el 12 de octubre, siendo esto obra del coronel Gaspar Aramayo. Además, advierte que según le han dicho, ni en Argentina hay tan buenos locales pero que aún faltaban maestros de postas que posean víveres y cultiven. Por ello solicita: “2.500 pesos en 100 personas a razón de 25 pesos y pagaderos al tercer año porque en los primeros dos años apenas prenderá la alfalfa por el mucho salitre" (Cajías, 1975: 81). Y, asimismo, pide al gobierno "9.540 pesos: 4.000 para 10 maestros de postas, a 400 cada uno; 150 mulas, 15 en cada posta y a 20 pesos cada una: 300 pesos y 2.540 para la siembra de alfalfa" (Cajías, 1975: 81).

Sin embargo, el testimonio de los posteros da cuenta que la habilitación de las postas no fue suficiente, así por ejemplo el postero Medinacele planteaba para 1834 que se marcharía a Chichas en busca de recursos, ya que "con cuantiosos gastos y mucha contracción, no hán correspondido a las esperanzas que tenía por que después de haber nacido la semilla se hán quemado las plantas en su 
principio sin duda por la naturaleza de las tierras" (ANB MI. Tomo 70, No 36, 1834).

La compleja situación de las postas es señalada cinco años más tarde por el Comisario de Guías de Cobija, Pío Ulloa, quien planteó:

Uno de los obstáculos al progreso de la Provincia Litoral que llama la atencion de todos y que se debe allanar con la prontitud posible, es el abandono de las postas de tránsito de ese Puerto. Ellas yacen tan arruinadas y despobladas, particularmente en la cordillera que el espacio de 42 leguas desde Viscachillas hasta Chiuchiu, no es mas que un horroroso y prolongado desierto. Sucederia lo mismo de Calama a Cobija, sino se hubiera conservado el Postero Bernardo Guanca, que con la mezquina asignación de diez pesos mensuales, mantiene, en un pié regular la de chacance: al menos con su personal asistencia, le proporcionan al viajero un asilo abierto, el combustible, y los aucilios que imperiosamente ecsije el arriezgado paso de la travesia (ANB MH. Tomo $\left.73, \mathrm{~N}^{\mathrm{o}} 12,1839\right)^{2}$.

Por tanto, desde la habilitación de las postas tanto postero como autoridades locales de Cobija dieron cuenta de la dificultad en el mantenimiento. En ese sentido, medidas tomadas por las primeras autoridades de Cobija como el desarrollo de la agricultura en el tramo más árido del camino dan cuenta del limitado conocimiento que estos tenían del paisaje. Sin embargo, pese a lo problemático de la ruta entre Cobija y tierras altas gracias a medidas como reducción de impuestos (Lofstrom, 1974), permitió que para fines de la década del 20 la totalidad de la exportación de plata de Bolivia se efectuara por Cobija, siendo este tipo de exportación el segundo egreso más importante del Estado boliviano (Cajías, 1975).

\section{Los arrieros}

La actividad arriería fue indispensable para el proyecto boliviano (Sanhueza 2002), ya que se constituyó junto con el puerto de Cobija en la puerta de entrada de la reciente Bolivia al resto del mundo. En ese sentido, dentro de las princiales medidas asociadas a la habilitación del puerto destaca el incentivo para ejercer de arriero en Atacama.
Poco a poco comenzó a desarrollarse una arriería profesional de carácter hacendal que según los planteamientos de Molina se

... inserta en el sector transporte de bienes y productos de las economías formales de exportación de ganado. En este contexto, los arrieros son trabajadores asalariados de los hacendados o prestan servicios de transporte. Se trata de una arriería empresarial o de "arrieros profesionales" que dan un servicio especializado (Molina 2011: 177).

Respecto de lo anterior, Arce señala que desde el inicio de Lamar:

Los arrieros y maestros de postas que se ocupaban en hacer el servicio de transporte estaban autorizados por el Gobierno para cobrar, como flete, un real y medio por legua por cada carga, ya fuese en mula o caballo, y medio y cuartillo por el postillón. Además, los maestros de postas percibían derechos de peaje a razón de un real por mula de carga y medio real por cada dos burros (Arce 1997:16).

Por lo demás, existen otros tipos de arriería de corte más tradicional correspondiente a aquella que se desarrolló independiente de los centros urbanos y los grandes comerciantes, constituyéndose como una arriería en donde los productos intercambiados y los animales utilizados, generalmente, eran de propiedad de estos mismos; y en donde parte de los recorridos diferían de los caminos establecidos por las autoridades, con el objetivo de evitar costes asociados (Molina 2011). Esto último queda fuera de análisis en este estudio considerando que su registro queda fuera del alcance de la estructura administrativa y consecuentemente de su documentación (Guerrero y Platt 2000, Molina 2011), siendo su investigación desde la perspectiva historiográfica muy dificultosa.

Más allá del tipo de arriería, esta actividad requirió de un alto grado de conocimiento del territorio, extendiéndose en Atacama desde la costa a la puna. Sin embargo, pese a su desarrollo costero, esta se concentró en "los habitantes de los oasis y valles a ambos lados de la cordillera. Las cargas se llevaban en asno hasta Calama y de allí en mula hasta Salta o Potosî" (Conti, 2006: 97). Asimismo, se observa 
una abundante presencia de arrieros de Tarapacá, Lípez y Chichas. Lo anterior da cuenta que el origen de los arrieros se encontraba, en muchas de las ocasiones, fuera de las fronteras nacionales, lo que es una clara evidencia de los límites difusos y permeables que se constituyó en el periodo inicial de las formaciones republicanas y de la rearticulación del espacio comercial tanto a partir de la lógica extractiva minera como de la herencia colonial e incluso prehispánicas (Letelier 2014).

En cuanto a la identidad de los arrieros durante la Colonia, esta actividad fue una de las principales ejercidas por los atacameños, sin embargo, para el periodo republicano su perfil sociocultural se encuentra escasamente estudiado (Molina 2011). En tal sentido, es posible plantear que una importante parte de los arrieros fueron atacameños, como plantean autores como Philippi (1860). Sin embargo, sería una problemática que debiese profundizarse a futuro.

Más allá de la adscripción étnica, uno de los aspectos más interesantes guarda relación con las formas de integración espacial que tuvieron los arrieros: integración que estuvo notoriamente cruzada por aspectos tradicionales. En ese sentido, considerando el registro del archivo Artola, la totalidad de los arrieros identificados provienen de tierras altas, situación que se da desde momentos coloniales (Sanhueza 1991) y que, creemos, guarda relación con la mantención de una tradición de movilidad prehispánica en donde la tendencia es que la población alteña baje y la población costera suba en menos ocasiones. Lo anterior se repite también en los Censos a inicios del periodo republicano, destacando que en 1840 únicamente un arriero vivía en Cobija; y en 1841, solo cinco (ANB MI. Tomo 87, $\mathrm{N}^{\circ}$ 26, 1840; ANB MI. Tomo 80, $\left.\mathrm{N}^{\mathrm{o}} 25,1841\right)$.

A lo anterior se suma la integración de personas no indígenas a estas redes de familias nativas que se asentaron en Atacama, destacando el caso de Calama. Así, esta ciudad se convirtió en un punto esencial de conexión, constituyéndose como un puerto cosmopolita, en donde fueron estableciéndose un grupo de comerciantes de diversa procedencia (Larraín 2008).

En tal sentido, en Atacama a medida que avanza el siglo XIX, como señala Larraín:

los no indígenas (nacionales bolivianos, chilenos y argentinos) se van adueñando de recursos territoriales originarios atacameños hasta convertirse en una reducida élite regional de terratenientes, comerciantes y mineros que dominan a los indígenas asentados en las dos cuencas (aunque menos claramente a los que vivían en la puna, asolada por montoneros) (Larraín 2008: 124).

Independiente del origen de los arrieros, la labor de estos requirió de un alto grado de especialización: el trayecto de Cobija a Potosí se hacía en un tiempo aproximado de 20 a 25 días y los recursos -por lo menos en los tramos de Atacama- eran bastante escasos. En ese sentido, el tramo de Cobija a Calama era de especialización entre los mismos arrieros.

El alto grado de especialización de los arrieros es también señalado por Arce (1997), quien planteó:

También es digno de mencionarse el hecho de que las recuas que se ocupaban de este tráfico conducían no solo mercaderías de uso corriente, sino también pesadas piezas de maquinarias para los ingenios mineros, y pianos completos que se importaban de Europa (Arce 1997: 15).

Posterior a 1832, con la declaración del puerto franco y la generación de un sistema de control más efectivo sobre la internación de productos, la relación entre arrieros y empresarios se institucionalizó bajo el alero del Estado-Nación. Aunque no encontramos contratos de exclusividad entre empresarios y arrieros, la regulación de pérdida o robo de carga fue penada, generándose así un acuerdo contractual.

Sin embargo, es factible pensar que la relación Casa Comercial/Arriero poseía ciertas condiciones de flexibilidad, las que se ven claramente reflejadas en el poco control efectivo de parte de las Casas Comerciales de los días de viaje y merma de carga, a excepción del transporte de la plata y el azogue, que constituían bienes fundamentales del Estado boliviano. Esta relación se vio enriquecida por alianzas que empresarios y arrieros establecían para ejercer el contrabando, estableciéndose circuitos de movilidad alternativos al oficial, especialmente a inicios de la década de 1830. Esto queda ejemplificado en septiembre de 1830 cuando los empresarios Francisco Arana, D. Rafael Beche y Garayo, se vieron implicados junto a un arriero en el contrabando de 
Tabla 1. Descripción de Gaspar Aramayo sobre las condiciones de las postas (ANB MI, Tomo 25, No 16, 1829).

\begin{tabular}{llc}
\hline \multicolumn{1}{c}{ Itinerario } & \multicolumn{1}{c}{ Características } & Leguas \\
\hline De Potosí a Sebadillas & Hay casas, pasto, cebada y leña, poblado & 4 \\
A Tocontaca & Solares, agua y leña. Despoblado, camino muy quebrado & 5 \\
A Churata & Poblado con toda comodidad & 7 \\
A Vicigsa & Poblado con toda comodidad & 6 \\
A Ollerías & Poblado con toda comodidad y hasta aquí todo el camino componible & 8 \\
A Agua de Castilla & Poblado con toda comodidad & 5 \\
A Amachuma & Con toda comodidad, despoblado y sus estancias distantes & 8 \\
A Puqyos & Despoblado, pozos de agua, pasto y leña & 8 \\
A Putitari & Con posta y toda comodidad & 8 \\
A Abilcha & Con posta y toda comodidad & 8 \\
A Talota & En el rodeo poblado con toda comodidad & 7 \\
A Viscachilla & Cordillera principia, con pasto, agua y leña & 7 \\
A Ascotán & Cordillera con agua, pasto y leña. Todo escaso sin incomodidad & 11 \\
A Polapi & Poblado con toda comodidad & 8 \\
A Santa Bárbara & Con agua, pasto y leña. Ya valle & 5 \\
A Chiuchiu & Capital del curato a toda comodidad. & 14 \\
A Calama & Pueblo con todo recurso & 8 \\
A Guacati & Con agua, pasto y leña & 10 \\
A Chacanci & Poblado con toda comodidad & 8 \\
A Culupo & Sin agua ni pasto. Todo desventajoso paraje de la travesía & 11 \\
A Cobija: Lamar & Por Tames & 13 \\
\hline
\end{tabular}

seis piñas supuestamente venidas desde Salta (ANB MH. Tomo 21, No 17, 1830).

Por tanto, la alta dependencia de empresarios, casas comerciales y el mismo gobierno a los arrieros permitió que estos alcanzaran notoriedad social. En ese sentido, tanto los empresarios como el gobierno fueron conscientes que los arrieros tenían el control real sobre sus bienes.

Pese al alto nivel de especialización que implicó la labor arriera, esta actividad vio dificultado su desarrollo en algunos períodos tanto por problemas de seguridad por disputas entre naciones como por la rentabilidad de la explotación minera, lo que generó migración laboral, especialmente a la minería. Por tanto, la actividad arriera era segura y, posiblemente, la minería una actividad temporal e inestable pero más rentable (ANB MH. Tomo 136, $\left.\mathrm{N}^{\circ} 28,1854\right)$.

No obstante, aunque el arrieraje fue la actividad eje para el desarrollo económico de Bolivia, en Cobija no alcanzó un desarrollo fluido como en otros puertos del Pacífico. Es más, fueron constantes las quejas sobre la falta de arrieros para efectuar el comercio en la zona. Como señalaba E. de La Torre (1841) comerciante de Valparaíso a José María Artola: "si hay alguna demora q. nunca será mayor, estimare tenga un poco de paciencia... La falta de arrieros nos ha perjudicado irreparablemente" (AA, 1841) ${ }^{3}$.

\section{Comentarios finales}

$\mathrm{El}$ arrieraje fue un elemento articulador fundamental para el desarrollo del capitalismo industrial durante el siglo XIX, constituyéndose en un tema de estudio que nos permite ver continuidades y cambio en cómo las poblaciones arrieras se relacionaron con su entorno.

En ese sentido, aunque el arriería se funda en formas de movimiento tradicional por el espacio andino este se vio modificado por el surgimiento de nuevos núcleos comerciales y mineros como Potosí, Salta y la misma Cobija, que redireccionaron la forma de moverse. Aunque se sabe que el uso de Cobija fue previo, su configuración como puerto oficial lo convirtió en un punto esencial para los arrieros, tanto para llevar la carga mineral como para la obtención de productos de consumo extranjeros. Así los arrieros, pese a las dificultades del tramo de Calama a Cobija, agregaron de forma más permanente este enclave costero.

Sin embargo, no se puede desconocer que estas nuevas prácticas de movilidad no dejan atrás por completo la tradición cultural previa que implicó, entre otros aspectos, el conocimiento y percepción del espacio andino y las relaciones sociales y de parentesco que en este contexto adquieren un carácter transfronterizo. 
En ese sentido, la importancia de los arrieros se sustentó en este nuevo contexto histórico social político y cultural, generando una nueva dinámica que gracias a la labor especializada y la importancia de esta actividad para el desarrollo económico de la zona permitió que el gremio alcanzara notoriedad social y económica con el tiempo.

No obstante, la conexión de tierras altas con el enclave de Lamar tuvo una corta historia. La falta de recursos, los problemas administrativos y las condiciones del desierto se conjugaron para que el desarrollo fluido de la arriería no fuese posible. Como plantea Carmagnani (2004), uno de los problemas cruciales - tanto de los nuevos como antiguos centros productivos de América Latina posteriores a los procesos de independencia- fue que no aprovecharon todas las ventajas de la libertad de comercio, ya que no se llevó a cabo una real modernización de las vías de comunicación internas, pese a la existencia de numerosos proyectos dirigidos a esto.
Finalmente, señalar que considerando el desarrollo posterior en la zona vemos que otros centros urbanos aledañas a Cobija, sobre todo Antofagasta, adquirieron hacia la década de 1870 una relevancia excepcional. Bajo este panorama es que habría que considerar que otros factores influyeron para que el puerto de Cobija terminara abandonado.

\section{Agradecimientos}

Agradezco al Archivo del Ministerio de Relaciones Exteriores de Chile y al Archivo Nacional de Bolivia por el acceso a sus dependencias y a los proyectos Fondecyt 1100951 y el proyecto Anillo Soc 1109 por su apoyo. Agradezco con especial aprecio a Manuel Almeyda, cuyos materiales fueron la inspiración de este trabajo y a Victoria Castro, Sergio González y Pablo Artaza, quienes fueron fundamentales para el desarrollo de esta investigación. Se extiende el agradecimiento a los evaluadores de este trabajo que permitieron esta publicación.

\section{Referencias Citadas}

Arce, I.

1997 [1930] Narraciones históricas de Antofagasta [2a edición]. Lama Industrial, Antofagasta.

Aldunate, C., Castro, V. y Varela, V.

2010 Los Atacamas y el pescado de Cobija en homenaje a John Víctor Murra. Chungara 42 (1): 341-347.

Ayllón, E.

2007 En torno a la desestructuración del espacio colonial andino: Bolivia 1825-1850. En: E. Cavieres. Del altiplano al desierto. Construcción de espacios y gestación del conflicto, pp. 41-81. Ediciones Universitarias de Valparaíso, Valparaíso.

Barra, B.

2006 Arriero en el partido del Maule (1700 - 1750). Revista Universum V21 $\mathrm{N}^{\circ} 1: 12-27$.

Brenna, J.E.

2010 De la frontera nacional a la frontera pluricultural. Frontera Norte, Vol. 22, No 44 : 265-276

Borie, C.

2013 De la pampa a la costa y de la costa a la pampa. Estudio de un espacio clave de la ruta entre Cobija y Calama. Memoria para optar al título de arqueólogo. Facultad de Ciencias Sociales, Universidad de Chile, Santiago de Chile. Cajías, F.

1975 La provincia de Atacama 1825-1842. Instituto Boliviano de Cultura, La Paz.

Castro, V.

1997 Huacca Muchay, evangelización y religión andina en Charcas de Atacama la baja. Tesis para optar al grado de Magíster en Etnohistoria, Facultad de Filosofía y Humanidades, Universidad de Chile, Santiago de Chile.
Castro, V.

2009 De ídolos a santos. Evangelización y religión andina en los Andes del sur. Fondo de Publicaciones Americanistas, Universidad de Chile. Centro de Investigaciones Diego Barros Arana y Dirección de Bibliotecas, Archivos y Museos, Santiago de Chile.

Castro, V., Aldunate, C. y Varela, V.

2012 Paisajes culturales de Cobija, costa de Antofagasta, Chile. Revista de Antropología, 26(2): 97-128.

Conti, V.

2003a Estrategias mercantiles, redes y migraciones de comerciantes durante el periodo rosista. Cuadernos de la Facultad de Filosofía y Ciencias Sociales, 21: 59-73.

Conti, V.

2003b El norte argentino y Atacama. Flujos mercantiles, producción y mercados en el siglo XIX. En: Benedetti, A. (comp.). Puna de Atacama. Sociedad, economía y frontera, pp. 21-52. Alción, Córdoba.

Conti, V.

2006 La ruta de los arrieros y el salitre. En: Las rutas del capricornio andino, editado por: A. Cabeza, M.I. Hernández, L. Núñez y M. Vásquez, pp. 93-104. Consejo de Monumentos Nacionales, Santiago de Chile.

Conti, V.

2008 Familia, Redes y Negocios en América del Sur (17901850 ), Nuevo Mundo Mundos Nuevos [En línea ], Simposios puesto en línea el 14 de enero de 2008 visitada 1 de marzo de 2015. URL: http: // NuevoMundo .revues.org / 17323; DOI: 10.4000 / nuevomundo. 17323

Conti, V.

2011 La frontera argentino-boliviana durante la temprana república. Complementariedad económica e integración 
social. Si somos americanos. Revista de estudios transfronterizos, XI (1): 13-40.

Conti,Viviana y Gabriela Sica.

Arrieros andinos de la colonia a la independencia. Nuevo Mundo Mundos Nuevos [En línea ] Debates, puesto en línea 31 de enero de 2011, consultado el 2 de marzo de 2015. URL: http: // NuevoMundo . revues.org/60560; DOI: 10.4000 / nuevomundo.60560

Guerrero, A. y T. Platt

2000 Proyecto antiguo, nuevas preguntas: La antropología histórica de las comunidades andinas cara al nuevo siglo. AHILA, Cuadernos 8: 95-113, Holanda.

Hidalgo, J.

1984 Complementariedad ecológica y tributo en Atacama (1683-1792). Estudios Atacameños $\mathrm{N}^{\circ}$ 7: 311-325.

Larraín, $\mathrm{H}$.

2008 Identidades y propiedades: transiciones territoriales e el siglo XIX atacameño. Estudios Atacameños, № 35: 119-139.

Letelier, J.

2014 La construcción social del Puerto de Cobija entre 1825 a 1847. Tesis para obtener al grado de Magíster en Historia, Facultad de Filosofía y Humanidades, Universidad de Chile, Santiago.

Lofstrom, W.

1974 Cobija, Bolivia's First Outlet to the Sea. The Americas, 31: 185-205.

Lofstrom, W.

1991 Cobija y el litoral boliviano. Visto por ojos extranjeros 1825-1880. Editorial Quipus, La Paz.

Lofstrom, W.

2011 La presidencia de Sucre en Bolivia, 3era ed. Instituto Internacional de Integración del Convenio Andrés Bello, Embajada de la República Bolivariana de Venezuela en el Estado Plurinacional de Bolivia, La Paz.

Mendieta, $\mathrm{P}$.

2006 Caminantes entre dos mundos: Los apoderados indígenas en Bolivia (Siglo XIX). Revista de Indias, vol. LXVI, núm. 2: 761-782.

Molina, R.

2011 Los otros arrieros de los valles, la puna y el desierto de Atacama. Chungara (Arica) vol. 43, № 2: 177-187.

Morales, $\mathrm{H}$.

2009 Etnopolítica en Atacama. Laberintos de la etnicidad atacameña en Chile. Tesis para optar al grado de doctor en Estudios Latinoamericanos, Universität Berlin, Berlín.
Murillo, D.

2011 Historia de Bolivia. Universidad Mayor de San Andrés, Facultad de Derecho y Ciencias Políticas, Carrera de Ciencia Política y Gestión, La Paz.

Murra, J.

2002 El control vertical de un máximo de pisos ecológicos en la economía de las sociedades andinas. En: El mundo andino. Población, medio ambiente y economía, pp. 85-125. Instituto de Estudios Peruanos, Lima.

Phillipi, A.

1860 Viage al Desierto de Atacama. Hecho de Orden del Gobierno de Chile en el verano de 1853-54. Libr. de Eduardo Anton, Halle en Sajonia.

Quintian, J. I.

2012 Una aristocracia republicana: la formación de la elite salteña, 1850-1870. Tesis doctorado en Historia, Universidad de San Andrés, Buenos Aires.

Sanhueza, M. C. y Gundermann, H.

2007 Estado, expansión capitalista y sujetos sociales en atacama (1879-1928). Estudios Atacameños, 34: 113-136.

Sanhueza, C.

1992a Estrategias readaptativas en Atacama: La arriería mulera colonial. En Etnicidad, economía y simbolismo en los Andes, Editado por: S. Arce, R. Barragán, L. Escobari y X. Medinacelli, pp. 363-385. Hisbol-IFEA-SBH, La Paz.

Sanhueza, C.

1992b Tráfico caravanero y arriería colonial en el siglo XVI. Estudios Atacameños No 10:173-187.

Sanhueza, C.

2011 Tráfico caravanero, arriería y trajines en Atacama colonial. Síntesis y discusiones sobre un proceso de adaptación andina. En: Temporalidad, interacción y dinamismo cultural. La búsqueda del hombre. Homenaje al Dr. Lautaro Núñez Atencio, Editado por: A. Hubert, J.A. González y M. Pereira, pp. 289-321. Ediciones Universitarias, Universidad Católica del Norte, Antofagasta.

Sanhueza, C.

2002 Capítulo Ocho. La tradición arriera de Atacama (siglo XIX). En: ATACAMA, pp. 236-257. Museo de Arte Precolombino, Santiago.

Sica, G.

2010 Del tráfico caravanero a la arriería colonial indígena en Jujuy. Siglos XVII y XVIII. Revista Transporte y Territorio $\mathrm{N}^{\circ} 3: 23-39$

\section{Notas}

1 Archivo Nacional de Bolivia (ANB), Ministerio del Interior (MI). De aquí en adelante todas las referencias

Ministerio de Hacienda (MH).
Archivo Artola (AA), Archivo personal de Manuel Almeyda. del documento van citadas en el texto. 